J. Amer. Soc. Hort. ScI. 115(4):681-686. 1990.

\title{
Leaf Color Variants from Coleus Shoot Cultures
}

\author{
Michael Marcotrigiano', Thomas H. Boyle ${ }^{2}$, Pamela A. Morgan ${ }^{3}$, and Karen L. Ambach ${ }^{4}$ \\ Department of Plant and Soil Sciences, University of Massachusetts, Amherst, MA 01003
}

Additional index words. Coleus $\times$ hybridus, somaclonal variation, epigenesis, chimeras, tissue culture, anthocyanin

\begin{abstract}
Nuclear-controlled leaf variegation was studied among Coleus $\times$ hybridus Voss (formerly C. blumei Benth.) cultivars propagated by seed and as shoot cultures on Murashige and Skoog (MS) medium + 1 to $3 \mathrm{mg}$ BA/liter. Cultivars tested possessed pattern chlorophyll variegation and either pattern or nonpattern anthocyanin variegation. The gene controlling an albino midrib region appears to be fairly stable, with only $2 \%$ of the micropropagated plantlets having a solid-green leaf characteristic, a characteristic that was always inherited following selfing. Pattern anthocyanin variegation (PAV) was fairly stable, while nonpattern anthocyanin variegation (NAV) was very unstable. In addition, variants from pattern-variegated phenotypes produced offspring identical to their parent following selfing In contrast, variants of nonpattern cultivars, when selfed, yielded offspring identical to the original cultivar, identical to the variant, or novel phenotypes. When variants were returned to culture, those derived from cultivars with PAV were more stable than those derived from nonpattern cultivars. In Coleus, micropropagation may induce epigenetic and/or heritable changes in leaf variegation. Cultivars with NAV are less stable than cultivars with PAV. Chemical names used; N-(phenylmethyl)-lH-purine-6-amine [benzyladenine (BA)].
\end{abstract}

Variegation can be defined as the presence of spots, streaks, or sectors of tissue of various colors on an organ or organism. In plants, variegation has been attributed to many causes and

Received for publication 12 June 1989. Paper no. 2957 of the Massachusetts Agricultural Experiment Station. The cost of publishing this paper was defrayed in part by the payment of page charges. Under postal regulations, this paper therefore must be hereby marked advertisement solely to indicate this fact.

'Associate Professor.

${ }^{2}$ Assistant Professor.

${ }^{3}$ Research Technician.

${ }^{4}$ Undergraduate Student. can have a genetic, physiological, morphological, or pathological basis (Kirk and Tilney-Bassett, 1978).

Variegated phenotypes can be classified as either pattern or nonpattern. In the former, color patterns are either present or absent in defined and predictable regions of an organ or organism. Examples include bicolored ray corollas of blanket flower (Gaillardia puchella) (Heywood, 1986) and bicolored fruit in

Abbreviations: ML, 'Magic Lace'; MR, 'Multicolor Rainbow'; NAM, no albino midrib; NAV, nonpattern anthocyanin variegation; PAV, pattern anthocyanin variegation; PCV, pattern chlorophyll variegation; RW, 'Rose Wizard'; SJ, 'Saber Jade'. 
ornamental gourds (Shifriss, 1981). With nonpattern variegation, numerous streaks, stripes, or spots of color are. distributed randomly throughout an organ. Examples include streaked anthocyanin formation in caryopses of some ornamental corn (Zea mays) lines (Federoff, 1983) and the red or purple streaks on the flower petals of some snapdragon (Antirrhinum majus) (Coen et al., 1986) and morning glory (Ipomoea purpurea) (Epperson and Clegg, 1987) genotypes.

Coleus $\times$ hybridus (Liberty Hyde Bailey Hortorium, 1976) is extensively cultivated for its brightly colored and variegated foliage. Foliar variegation in coleus is caused by differences in the distribution and levels of chlorophyll and/or anthocyanins. Observations of seed-propagated commercial cultivars indicate the presence of both pattern and nonpattern types of foliar variegation. Previous investigations have determined that control of variegation in coleus is nuclear and, in most cases, simply inherited (Boye, 1941; Boye and Rife, 1938; Rife, 1940, 1944, 1945, 1948).

The following experiments were conducted to determine the stability of foliar variegation among several cultivars of C. $\times$ hybridus plants. In this respect, we wished to determine the phenotypic stability of pattern and nonpattern variegation following sexual reproduction and in vitro shoot proliferation from axillary buds.

Our report describes a simple system for the induction of phenotypic variation that may have potential application for those interested in studying the causes of genetic variability in plant tissue culture and the genetics of NAV.

\section{Materials and Methods}

Plant material. Four seed-propagated coleus cultivars ['Magic Lace' (ML), 'Multicolor Rainbow' (MR), 'Saber Jade' (SJ), and 'Rose Wizard' (RW) (George W. Park Seed Co., Greenwood, S.C.)] were used as parental material. Leaves of SJ and RW have an albino midrib, i.e., a large chlorophyll-free region surrounding the midrib (Fig. $1 \mathrm{~A}$ and $\mathrm{C}$ ); this type of variegation is hereafter referred to as PCV. In addition, anthocyanins are present in the adaxial epidermis of RW leaves and pigmentation is present in a zone surrounding the midrib but absent along the leaf edge (Fig. 1A); this type of variegation is hereafter referred to as PAV. Leaves of ML and MR have an albino midrib (PCV) similar to but more diffuse than leaves of SJ and RW. In contrast, leaf anthocyanin pigmentation of ML and MR occurs as small spots, streaks, or large sectors randomly distributed throughout the lamina. The red markings can appear on both adaxial and abaxial surfaces and follow cell lineages (Fig. $1 \mathrm{E}$ and $\mathrm{J}$ ); this type of variegation is hereafter referred to as NAV.

For each cultivar, a single seedling expressing the foliar variegation typical of the cultivar was randomly selected and clonally propagated by rooting terminal vegetative stem cuttings. All further experiments used clonal material derived from these single-plant selections. Three experiments were conducted.

\section{Phenotypic status of shoots derived from in vitro propagation (Expt. 1)}

Culture conditions. Cultures for all experiments were maintained in a growth room at $24 \pm 3 \mathrm{C}$. Irradiance was provided by cool-white fluorescent lamps $\left(35 \mu \mathrm{mol} \cdot \mathrm{s}^{-1} \cdot \mathrm{m}^{-2}\right.$ photosynthetic photon flux) using a 16-hr photoperiod (24-hr cycle).

Initiation of shoot cultures. Techniques used to develop shoot cultures of $C . \times$ hybridus were those of Morgan and Marcotrigiano (1987). Briefly, explants consisted of $0.5-\mathrm{cm}$ stem sec- tions, each containing a single node. Leaves were removed and nodal segments were surface sterilized by immersion for $10 \mathrm{~min}$ in $0.5 \%$ sodium hypochlorite solution (10\% Clorox) containing $0.8 \%$ Tween 20 as a surfactant. After three rinses in sterile distilled water, bleached (i.e., dead) tissue was excised and single-node explants were placed in 25-mm-diam test tubes containing hormone-free MS basal medium (Murashige and Skoog, 1962) solidified with 8 g Difco Bacto-agar/liter.

Shoot proliferation and rooting. Shoot tips (5 to $10 \mathrm{~mm}$ long) were excised from shoots growing on hormone-free medium and placed on MS medium containing $3 \mathrm{mg}$ BA/liter. After 21 days in proliferation medium, shoots were separated and subculture. Following three subcultures, shoots were transferred to MS medium containing $1 \mathrm{mg} \mathrm{BA} /$ liter to increase shoot size to facilitate shoot separation before rooting. Shoots were removed from culture after 21 days and rooted on hormone-free MS medium. After transplanting, plants were acclimated to ambient conditions under clear plastic tents and transferred to the greenhouse. Five months later, plants were phenotypically classified into general categories based on foliar variegation patterns and coloration. All plants possessing more than one distinct phenotype (i.e., chimeral in appearance) were placed in a single category.

\section{Evaluation of progeny obtained from self-pollination of cultivars and selected variants derived from tissue culture (Expt. 2)}

Clonal stock of each cultivar and selected variants from tissue culture were self-pollinated in the greenhouse. Progeny derived from self-pollinated cultivars will be designated as $S_{1}$, while progeny derived from selfed variants will be designated as $R_{1}$. Plants were isolated from each other by a minimum distance of $4 \mathrm{~m}$, and pollinations were performed only during the winter months to eliminate contamination by insect pollinators. Individual inflorescences were hand-pollinated every few days until all florets senesced. Seed of each cultivar and selected variants were sown and seedlings were phenotypically analyzed (described under Expt. 1) when plants were $\approx 15 \mathrm{~cm}$ high.

\section{Phenotypic status of variants returned to culture (Expt. 3)}

To determine the phenotypic stability of selected variants derived from tissue culture (Expt. 1), axillary shoots from variants were returned to culture. Shoots of original, single-plant selections of each cultivar served as controls. Procedures identical to those described under Expt. 1 were employed, except that unrooted shoots derived from a final transfer on hormone-free medium were rooted ex vitro under clear polyethylene tents.

\section{Results and Discussion}

\section{Phenotypic status of shoots derived from in vitro propagation (Expt. 1)}

Multiplication rate was three to four shoots per shoot per transfer for all cultivars tested. Differences in final shoot count were due largely to contamination early in the multiplication phase.

Phenotypic analyses of plants derived from shoot cultures indicated that cultivars with pattern variegation were more stable than those with nonpattern variegation, with the former resulting in $1 \%$ to $2 \%$ variants and the latter $62 \%$ to $72 \%$ variants (Table 1). Among nonpattern cultivars, many distinct classes of variants were recovered. Some variants from ML possessed solid- 


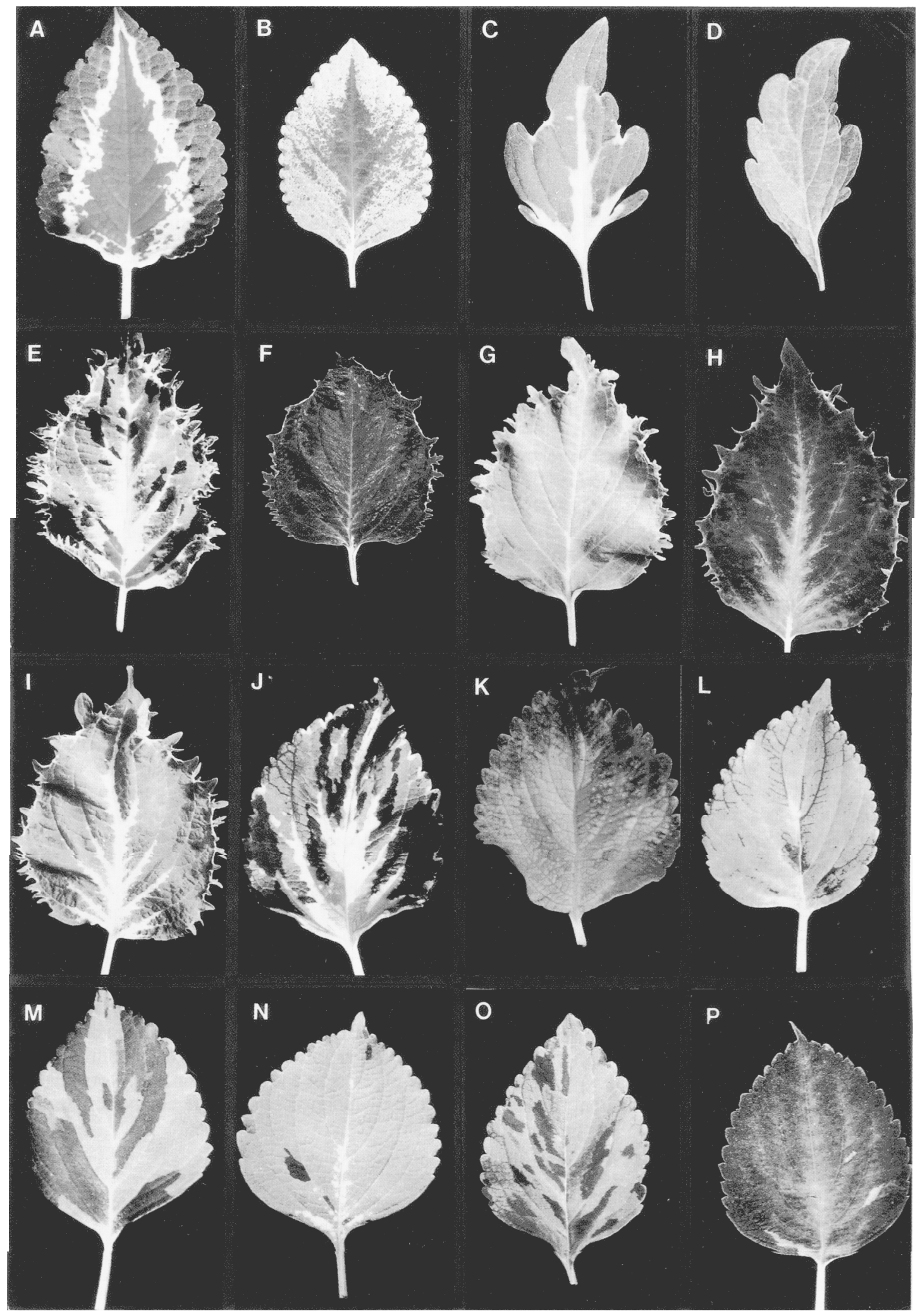

Fig. 1. Single leaves of Coleus, typical of leaves on whole plants (see Table 2 for abbreviations). (A) RW (B) RW-NAM, (C) SJ, (D) SJNAM, (E) ML, (F) ML-R, (G) ML-G, (H) ML-RP, (I) ML-GY, (J) MR, (K) MR-ER, (L) MR-YGRV, (M) MR-RY, (N), (O), (P) leaves from plants that are self-progeny of MR-RY. Distribution and level of anthocyanin are stable on each of these plants even after 18 months of vegetative propagation.

color leaves with respect to the presence of foliar anthocyanins and/or the albino midrib region (Fig. 1 F, G, H, I). Many complex and intermediate phenotypes were observed, including plants with less- or more-extensive NAV, plants with anthocyanins restricted to the leaf veins (Fig. 1L), and plants with a brown or maroon overcast (Fig. 1K). In a few cases, plants 
Table 1. Phenotypic status of shoot culture-derived coleus plants.

\begin{tabular}{lccccccc}
\hline \hline & $\begin{array}{c}\text { Variegation } \\
\text { phenotype }\end{array}$ & & $\begin{array}{c}\text { No. } \\
\text { plants }\end{array}$ & \multicolumn{2}{c}{$\begin{array}{c}\text { No. distinct } \\
\text { classes of } \\
\text { Cultivar }\end{array}$} & $\begin{array}{c}\text { PCV PAV NAV } \\
\text { plants }\end{array}$ \\
\cline { 2 - 6 } Saber Jade & + & - & - & 103 & 1 & 1 \\
Rose Wizard & + & + & - & 207 & 2 & 2 \\
Multicolor Rainbow & + & - & + & 363 & 7 & 62 \\
Magic Lace & + & - & + & 157 & 16 & 72 \\
\hline
\end{tabular}

Presence $(+)$ or absence $(-)$ of variegation phenotype. See text for definition of these designations.

appeared to be chimeral and possessed large sectors of one phenotype, while the remainder of the plant was typical of the cultivar. For all micropropagated plants, phenotypic variation was observed only for leaf color, whereas all other morphological characteristics were identical to the respective cultivar (data not presented).

Expression of PAV was stable, with no variants recovered for this trait. Studies conducted by Rife and Boye (1940) indicated PAV phenotype is determined by the $P$ gene in which the allele $p$ (PAV phenotype) is recessive to $P$ (entirely red leaves) and to $p^{G}$ (entirely green leaves). In contrast, expression of the gene controlling NAV (expressed in ML and MR) was highly unstable. Liebowitz and Kloth (1986) have speculated that this phenotype may be controlled by a transposable genetic element, although to our knowledge a thorough genetic analysis of NAV in coleus has not been reported. Expression of the PCV phenotype was intermediate in stability. Presence of PCV has been reported to be controlled by a single recessive gene (Liebowitz, 1985). The PCV phenotype was less stable in MR and ML than in RW, and several plants were recovered from MR and ML that possessed extensive albino leaf tissue, a characteristic that resulted in slow growth and/or premature death. Hervey and Robbins (1978) also reported phenotypic variation for the extent of midvein chlorosis from plants regenerated from cultured leaf tissue of two coleus genotypes possessing PCV.

Variants that were selected for further analysis (Expts. 2 and 3 ) are described in Table 2 and pictured in Fig. 1.

\section{Evaluation of progeny obtained from self-pollination of cultivars and selected variants derived from tissue culture (Expt. 2)}

Self-fertilization of SJ and RW yielded populations phenotypically identical to the parent. In addition, all $\mathrm{R}_{1}$ progeny of SJ-NAM and RW-NAM were identical to the parent, indicating homozygosity for factors controlling leaf pigmentation (Table 3). MR segregated for leaf variegation, with $5 \%$ of the $S_{1}$ progeny expressing a distinctly different phenotype, i.e., a larger albino midrib region. However, anthocyanin pigmentation in all the $S_{1}$ seedlings was nonpatterned and phenotypically similar to the parent cultivar. This result is in contrast to data reported by Rife (1944), who observed non-Mendelian ratios for leaf pigmentation and variegation pattern following the selfing of an unnamed coleus clone expressing NAV. The ML clone could not be selfed due to male sterility, a condition frequently linked to the fringed leaf-edge phenotype (Rife, 1940).

Upon selfing, variants of MR yielded numerous $R_{1}$ phenotypes, none of which resembled the parent but many of which were phenotypically identical to MR (Table 3). Some of the original variants were phenotypically distinct, possibly because of epigenetic effects. Dougall et al. (1980) demonstrated that carrot clones selected from tissue culture for their accumulation of anthocyanins were not mutants and frequently gave rise to cell clones identical to the original phenotype in that they did not accumulate anthocyanins. Alternatively, our coleus may have been chimeral and possessed nonmutant cells in the histogen responsible for the production of gametes and, therefore, seed. Rife (1948) self-pollinated a single chimeral coleus plant that possessed branches with PAV (in a heterozygous state) and solidgreen branches. The progeny of both variegated and green branches segregated 3 solid green to 1 PAV. He concluded that the mutation may have been present only in the somatic tissue. This observation is important and a similar phenomenon may have influenced our results. Synthesis and accumulation of anthocyanins are often tissue-specific and only expressed in the epidermis, even if all cells contain the genes necessary for their formation (Sagawa and Mehlquist, 1957). Therefore, a greenleaved plant possibly may be a periclinal chimera with an epidermis that no longer contains the genes necessary for anthocyanin formation. However, the leaves would still appear green even if the subtending cell layers did possess the genetic potential for anthocyanin formation. Since in dicots, the reproductive cells generally arise from subepidermal cell lines (Stewart and Burk, 1970), such chimeras may pass the genes for anthocyanin formation to their progeny. The progeny, being of single-cell origin (i.e., the fertilized egg), would be phenotypically distinct from the chimera and could appear typical of the cultivar. The above description could easily be misinterpreted as an epigenetic event, when in actuality it is a combination of tissue-specific gene expression and chimerism. "Reversions" in culture could also be explained by rearrangements or displacements of cell

Table 2. Description and code for selected variants derived from shoot cultures.

\begin{tabular}{|c|c|c|}
\hline Original cultivar & Variant & Variant description \\
\hline Saber Jade & SJ-NAM & Identical to cultivar but leaf entirely green; no albino midrib \\
\hline Rose Wizard & RW-NAM & Identical to cultivar but without albino midrib \\
\hline \multirow{4}{*}{ Magic Lace } & ML-R & Leaf entirely red; no albino midrib \\
\hline & $\dot{M} L-G$ & Leaf entirely green; no albino midrib; no anthocyanin. \\
\hline & ML-RP & $\begin{array}{l}\text { Anthocyanin throughout; albino midrib present, giving appearance of a red leaf } \\
\text { with a pink center. }\end{array}$ \\
\hline & ML-GY & Leaf green with albino midrib; no anthocyanins. \\
\hline \multirow[t]{3}{*}{ Multicolor Rainbow } & MR-ER & $\begin{array}{l}\text { Leaves almost entirely red but pigmentation is incomplete, revealing green sec- } \\
\text { tors; albino midrib region present but somewhat masked by overlying red. }\end{array}$ \\
\hline & MR-YGRV & $\begin{array}{l}\text { Leaves very yellow due to extensive albino midrib; red regions generally con- } \\
\text { fined to veins. }\end{array}$ \\
\hline & MR-RY & $\begin{array}{l}\text { Same anthocyanin distribution as parent, but albino midrib region (yellow) greatly } \\
\text { reduced. }\end{array}$ \\
\hline
\end{tabular}


Table 3. Analysis of $S_{1}$ and $R_{1}$ progeny derived from three coleus cultivars and selected variants.

\begin{tabular}{lcccc}
\hline \hline & $\begin{array}{c}\text { Progeny } \\
\text { identical } \\
\text { Cultivar or }\end{array}$ & $\begin{array}{c}\text { No. } \\
\text { to parents } \\
(\%)\end{array}$ & $\begin{array}{c}\text { No. variant } \\
\text { phenotype } \\
\text { classes }\end{array}$ & $\begin{array}{c}\text { Progeny } \\
\text { identical } \\
\text { to original } \\
\text { cultivary } \\
(\%)\end{array}$ \\
\hline Saber Jade & 56 & 100 & 0 & 100 \\
SJ-NAM & 55 & 100 & 0 & 0 \\
Rose Wizard & 79 & 100 & 0 & 100 \\
RW-NAM & 90 & 100 & 0 & 0 \\
Multicolor Rainbow & 88 & 95 & 1 & 95 \\
MR-ER & 52 & 0 & 3 & 82 \\
MR-YGRV & 47 & 0 & 5 & 46 \\
MR-RY & 77 & 0 & 7 & 56 \\
\hline
\end{tabular}

${ }^{2}$ One hundred seeds sown, all germinated seedlings were evaluated. ${ }^{y}$ Saber Jade, Rose Wizard, or Multicolor Rainbow.

Table 4. (Expt. 3). Phenotypic analysis of shoot culture-derived Coleus plants derived from four cultivars and selected variants originating from Expt. 1.

\begin{tabular}{lcccc}
\hline \hline & $\mathrm{n}$ & $\begin{array}{c}\text { Identical to } \\
\text { explant } \\
(\%)\end{array}$ & $\begin{array}{c}\text { No. variant } \\
\text { phenotypic } \\
\text { classes }\end{array}$ & $\begin{array}{c}\text { Typical } \\
\text { of } \\
\text { cultivar } \\
(\%)\end{array}$ \\
\hline Explant & 129 & 86 & 2 & 86.0 \\
Saber Jade & 118 & 95 & 1 & 0.05 \\
SJ-NAM & 149 & 81 & 3 & 81.0 \\
Rose Wizard & 124 & 90 & 2 & 0.02 \\
RW-NAM & 212 & 10 & 9 & 10 \\
Multicolor Rainbow & 20 & 55 & 1 & 0 \\
MR-ER & 133 & 50 & 4 & 0 \\
MR-YGRV & 93 & 53 & 3 & 0 \\
MR-RY & 187 & 4 & 7 & 4 \\
Magic Lace & 326 & 78 & 3 & 0 \\
ML-G & 213 & 58 & 3 & 0 \\
ML-R & 338 & 75 & 5 & 0 \\
ML-GY & 194 & 89 & 4 & 0 \\
ML-RP & & & &
\end{tabular}

layers in the shoot apices of tissue-cultured chimeral plants and may not be caused by genetic changes.

There were several new phenotypes recovered from $R_{1}$ populations of MR variants. The seedling population of MR-RY was particularly interesting, since it yielded several seedlings that differed only in their degree of NAV, and formed a continuum from nearly solid green to nearly solid red (Fig. 1 N,O,P). Similarly, unstable mutants with enhanced or decreased anthocyanin production (Love and Malone, 1967) or a change from PAV to NAV (Love and Constantin, 1966) have been recovered following fast-neutron irradiation of 'Scarlet Red' coleus.

\section{Phenotypic status of variants returned to culture (Expt. 3)}

As in Expt. 1, SJ and RW were fairly stable in culture (Table 4). The variants SJ-NAM and RW-NAM were more stable, with only $5 \%$ to $10 \%$ of the micropropagated plants being phenotypically dissimilar to the explant source. The most common variation was a reversion to the phenotype of the cultivar or apparent chimerism, i.e., plants that possessed a sector with leaves containing an albino midrib and a sector without the albino midrib. Variants of MR were unstable when returned to culture, with only $50 \%$ to $55 \%$ of the micropropagated plants phenotypically identical to the variant, but were more stable than the original cultivar. There were no reversions to the phenotype of the cul- tivar, and some of the variants recovered were different than those recovered in Expt. 1. Only 4\% of the plants derived from ML were phenotypically indistinguishable from the cultivar, whereas $58 \%$ to $89 \%$ of the shoots derived from the ML variants were identical to the explant. Apparently, the original change in phenotype resulted in a more stable condition. Plants derived from the variants of ML were more stable than those obtained from the variants of MR. The ML variants chosen were either solid or patterned and may, therefore, have been more stable.

Plant tissue culture has become increasingly popular as a commercial means of clonal propagation. Because plants regenerated from organs or cell cultures frequently display phenotypic variation (Earle and Demarly, 1982), shoot tips or axillary buds are the preferred explant source when uniformity is desired. However, we have demonstrated that this technique can result in high levels of variability in certain genotypes.

Our results indicate that, in Coleus $\times$ hybridus, the two types of anthocyanin variegation (i.e., pattern and nonpattern) are distinctly different in terms of their phenotypic and genotypic stability in tissue culture. Conventional clonal micropropagation procedures appear to severely "disrupt" genetic expression in NAV cultivars. Whether this result is caused by the activation of a mobile genetic element, as has been recently reported in regenerants from maize tissue culture (Peschke et al., 1988), remains to be determined. Our results are strikingly similar to those in a lengthy report by Stout (1915), who painstakingly followed the clonal origin of several somatic mutations in an unnamed cutting-propagated coleus clone similar in description to MR. While the frequency of phenotypic change reported by Stout was much less than in our study, the phenotypic descriptions and patterns of inheritance were very similar, suggesting that the tissue culture process may act to enhance the frequency of change in a genome predisposed to change. This phenomenon has been reported in alfalfa (Groose and Bingham, 1986a).

Unlike other reports in which mutable genes have been reported to result in stable revertants (Groose and Bingham, 1986b), our' "reculture" experiments yielded additional variation at high frequency. The genetic cause of such persistent variability upon reculture has yet to be determined.

\section{Literature Cited}

Boye, C.L. 1941. An allelic series in Coleus. J. Gen. 42:191-197.

Boye, C.L. and D.C. Rife. 1938. Genetic studies of coleus. I. Leaf color I. J. Hered. 29:55-60.

Coen, E.S., R. Carpenter, and C. Martin. 1986. Transposable elements generate novel spatial patterns of gene expression in Antirrhinum majus. Cell 47:285-296.

Dougall, D.K., J.M. Johnson, and G.H. Whitten. 1980. A clonal analysis of anthocyanin accumulation by cell cultures of wild carrot. Planta 149:292-297.

Earle, E.D. and Y. Demarly. 1982. Variability in plants regenerated from tissue culture. Praeger, New York.

Epperson, B.K. and M.T. Clegg. 1987. Instability at a flower color locus in morning glory. J. Hered. 78:346-352.

Fedoroff, N.V. 1983. Controlling elements in maize, p. 1-63. In: J.A. Shapiro (ed.). Mobile genetic elements. Academic, New York.

Groose, R.W. and E.T. Bingham. 1986a. An unstable anthocyanin mutation recovered from tissue culture of alfalfa (Medicago sativa). 1. High frequency of reversion upon reculture. Plant Cell Rpt. 5:104107.

Groose, R.W. and E.T. Bingham. 1986b. An unstable anthocyanin mutation recovered from tissue culture of alfalfa (Medicago sativa). 2. Stable nonrevertants derived from reculture. Plant Cell Rpt. 5:108110

Hervey, A. and W.J. Robbins. 1978. Development of plants from leaf 
discs of variegated Coleus and its relation to patterns of leaf chlorosis. In Vitro 14:294-300.

Heywood, J.S. 1986. Edaphic races of Gaillardia puchella in central Texas. J. Hered. 77:146-150.

Kirk, J.T.O. and R.A.E. Tilney-Bassett. 1978. The plastids. Elsevier/ North-Holland Biomedical, Amsterdam.

Liberty Hyde Bailey Hortorium. 1976. Hortus third: A concise dictionary of plants cultivated in the United States and Canada. 3rd ed. Macmillan, New York.

Liebowitz, R.J. 1985. The genetics and breeding of coleus. Plant Breed. Rev. 3:343-360.

Liebowitz, R.J. and R.H. Kloth. 1986. Genetics of foliar variegation in coleus. J. Hered. 77:125-126.

Love, J.E. and M.J. Constantin. 1966. The induction of bud sports in Coleus blumei by fast neutrons. Proc. Amer. Soc. Hort. Sci. 88:627630.

Love, J.E. and B.B. Malone. 1967. Anthocyanin pigments in mutant and nonmutant Coleus plants. Radiation Bot. 7:549-552.

Morgan, P.A. and M. Marcotrigiano. 1987. A demonstration of genetic variation caused by plant tissue culture. J. College Sci. Teaching 17(3):216-219.

Murashige, T. and F. Skoog. 1962. A revised medium for rapid growth and bioassay with tobacco tissue cultures. Physiol. Plantarum 15:473497.
Peschke, V.A., R.L. Phillips, and B.G. Gengenbach. 1988. Discovery of transposable element activity among progeny of tissue culture derived maize plants. Science 238:804-807.

Rife, D.C. 1940. Genetic studies of Coleus. II. Leaf form and a bud mutation. J.Hered. 31:293-296.

Rife, D.C. 1944. The genetics of certain common variations in Coleus. Ohio J. Sci. 44:18-24.

Rife, D.C. 1945. A series of five multiple alleles. Ohio J. Sci. 45:13.

Rife, D.C. 1948. Simply inherited variations in coleus. J. Hered. 39:8591.

Rife, D.C. and C.D. Boye. 1940. The genetics of certain leaf variations in Coleus blumei. Genetics 25: 132-133. (Abstr.)

Sagawa, Y. and G.A.L. Mehlquist. 1957. The mechanism responsible for some X-ray induced changes in flower color of the carnation, Dianthus caryophyllus. Amer. J. Bot. 44:397-403.

Shifriss, O. 1981. Origin, expression, and significance of gene $B$ in Cucurbita pepo L. J. Amer. Soc. Hort. Sci. 106:220-232.

Stewart, R.N. and L.G. Burk. 1970. Independence of tissues derived from apical layers in ontogeny of the tobacco leaf and ovary. Amer. J. Bot. 57:1010-1016.

Stout, A.B. 1915. The establishment of varieties in coleus by the selection of somatic variations. Carnegie Institution of Washington, Publ. 218. 